\title{
Qualidade de maçãs 'Gala' armazenadas em atmosfera controlada dinâmica e estática com renovação do ar
}

\author{
Quality of 'Gala' apples stored in dynamic and static controlled \\ atmosphere with air renovation
}

\author{
Auri Brackmann ${ }^{1}$ Ricardo Fabiano Hettwer Giehl ${ }^{2}$ Josuel Alfredo Vilela Pinto ${ }^{3}$ \\ Cristiano André Steffens ${ }^{4}$ Ivan Sestari ${ }^{5}$
}

\section{- NOTA -}

RESUMO

Este experimento teve como objetivo avaliar o efeito da remoção periódica da atmosfera das câmaras de atmosfera controlada com ar e nova instalação, bem como o uso da atmosfera dinâmica, sobre a manutenção da qualidade da maçã 'Gala'. Os tratamentos utilizados foram: (1) controle (sem renovação); (2) renovação da atmosfera diariamente durante o resfriamento dos frutos; (3) renovação da atmosfera diariamente durante o resfriamento e mensalmente no período de armazenamento em atmosfera controlada; (4) renovação da atmosfera mensalmente; (5) $50 \mu \mathrm{L} \mathrm{L} \mathrm{L}^{-1}$ de etileno no interior da câmara; e (6) atmosfera dinâmica (injeção diária de $N_{2}$ para remoção do $\mathrm{CO}_{2}$ ). Após oito meses de armazenamento, o tratamento com renovação da atmosfera diariamente durante o resfriamento e mensalmente no período de armazenamento em atmosfera controlada proporcionou frutos com maior firmeza de polpa. Nenhuma das técnicas avaliadas permitiu manter os níveis de etileno nas câmaras de armazenamento abaixo de $5 \mu \mathrm{L} L^{-1}$. Provavelmente, a absorção do etileno proporciona um benefício igual ou maior com um menor custo, pois a renovação da atmosfera implica altos custos na aquisição de nitrogênio.

Palavras-chave: armazenamento, Malus domestica Borkh., póscolheita, etileno.

\begin{abstract}
This experiment was carried out aiming to evaluate the effect of periodical removal of the atmosphere of controlled atmosphere chambers with fresh air and the use of dynamic atmosphere on quality of 'Gala' apples. Evaluated treatments were: (1) control (without air renovation); (2) daily atmosphere renovation during fruit cooling; (3) daily atmosphere renovation during cooling and monthly during controlled atmosphere storage of fruits; (4) monthly atmosphere renovation; (5) $50 \mu \mathrm{L} \mathrm{L}^{-1}$ ethylene inside chamber; and (6) dynamic atmosphere $\left(\mathrm{N}_{2}\right.$ injection to remove $\mathrm{CO}_{2}$ ). After eight months of storage, daily atmosphere renovation during cooling and monthly during controlled atmosphere storage maintained fruit firmness. None of the evaluated techniques allowed ethylene levels below $5 \mu \mathrm{L} \mathrm{L}^{-1}$ inside the storage chambers. Probably, ethylene scrubbing has an equal or higher benefit than air renovation, with lower costs, because atmosphere renovation involves higher costs with nitrogen purchase.
\end{abstract}

Key words: storage, Malus domestica Borkh., postharvest, ethylene.

A maçã 'Gala' apresenta, em relação às outras cultivares, alta taxa respiratória e elevada

\footnotetext{
${ }^{1}$ Engenheiro Agrônomo, Doutor, Professor Adjunto, Departamento de Fitotecnia, Universidade Federal de Santa Maria (UFSM), 97105900, Santa Maria, RS. E-mail: brackmann@ccr.ufsm.br (autor para correspondência).

${ }^{2}$ Acadêmico do curso de Agronomia, UFSM, Bolsista do Conselho Nacional de Desenvolvimento Científico e Tecnológico (CNPq).

${ }^{3}$ Acadêmico do curso de Agronomia, UFSM, Bolsista da Fundação de Amparo à Pesquisa do Estado do Rio Grande do Sul (FAPERGS).

${ }^{4}$ Engenheiro Agrônomo, MSc em Agronomia, doutorando do Programa de Pós-graduação em Agronomia (PPGA), UFSM, Bolsista da Coordenação de Aperfeiçoamento de Pessoal de Nível Superior (CAPES).

${ }^{5}$ Engenheiro Agrônomo, mestrando do PPGA, UFSM. Bolsista CNPq.
} 
produção de etileno, sendo que a eliminação deste gás, durante o armazenamento em atmosfera controlada, proporciona frutos com maior firmeza de polpa e acidez titulável, exibindo cor de fundo da epiderme mais verde (BRACKMANN , 1992). A concentração de $1 \mu \mathrm{L} \mathrm{L}^{-1}$ de etileno já é suficiente para a promoção do amadurecimento em maçãs (KADER, 1992). Principalmente nos EUA e, em menor escala na Europa, utiliza-se a atmosfera controlada dinâmica, em que se injeta constantemente ou intermitentemente o $\mathrm{N}_{2}$, em forma de gás, nas câmaras de $\mathrm{AC}$, eliminando o $\mathrm{CO}_{2}$ através do princípio da diluição, o que poderia também diluir e remover o etileno liberado pelos frutos, apresentando um efeito semelhante a um equipamento removedor de etileno. Este nitrogênio é obtido através de equipamentos de PSA ("Pressure Swing Adsorption"), membranas separadoras de ar ou, ainda, como resto na produção industrial de oxigênio (BRACKMANN \& LUNARDI, 1996). Da mesma forma, a renovação do ar poderia ser eficiente para a remoção do etileno presente nas câmaras de armazenamento. No entanto, não existe na literatura informações sobre o efeito do uso da atmosfera dinâmica e da renovação do ar na manutenção da qualidade da maçã 'Gala'.

Dessa forma, este experimento teve como objetivo avaliar o efeito da renovação da atmosfera das câmaras de atmosfera controlada com ar e nova instalação da atmosfera, através de injeção de nitrogênio, e o uso da atmosfera dinâmica, com a remoção diária de $\mathrm{CO}_{2}$ através da injeção de nitrogênio, sobre a manutenção da qualidade da maçã 'Gala'.

O experimento foi conduzido no Núcleo de Pesquisa em Pós-Colheita do Departamento de Fitotecnia da UFSM com frutos da cv. Gala, provenientes de pomar comercial da empresa Renar (Fraiburgo, SC). O delineamento experimental utilizado foi o inteiramente casualizado com quatro repetições contendo 25 frutos cada. Os tratamentos avaliados foram: (1) controle (sem renovação); (2) renovação da atmosfera diariamente durante o resfriamento; (3) renovação da atmosfera diariamente durante o resfriamento e mensalmente no período de armazenamento em atmosfera controlada; (4) renovação da atmosfera mensalmente; (5) injeção de $50 \mu \mathrm{L} \mathrm{L}^{-1}$ de etileno no interior da câmara (para simular a situação que ocorre nas câmaras de atmosfera controlada das empresas de armazenamento de maçãs 'Gala', que não utilizam absorvedores de etileno); e (6) atmosfera dinâmica (injeção de $\mathrm{N}_{2}$ para a remoção do $\mathrm{CO}_{2}$ ). Antes da instalação da atmosfera controlada, os frutos foram resfriados lentamente até atingirem a temperatura de armazenamento (sete dias). A renovação da atmosfera, durante o resfriamento, foi realizada por meio da injeção de ar numa quantidade correspondente a quatro vezes o volume interno das minicâmaras onde estavam os frutos dos tratamentos 2 e 3 . Esse procedimento foi efetuado através de uma bomba de membrana, que fez circular o ar de fora da minicâmara para seu interior, eliminando, por diluição, parte da atmosfera interna. O tempo que a bomba permaneceu acionada foi determinado em função do volume livre das minicâmaras $\left(\mathrm{V}_{\text {livre }}\right)$ e da vazão da bomba, segundo a fórmula: tempo $=\left(\mathrm{V}_{\text {livre }} \mathrm{x} 4\right)$ / vazão da bomba. Após sete dias nessas condições, foi instalada a atmosfera controlada com pressões parciais de $1,2 \mathrm{kPa} \mathrm{O}_{2}$ e $2,5 \mathrm{kPa} \mathrm{CO}_{2}$, à temperatura de $0,5^{\circ} \mathrm{C}$ $( \pm 0,1)$. A renovação da atmosfera nas minicâmaras, que continham os frutos dos tratamentos 3 e 4 , foi efetuada mensalmente de forma semelhante ao descrito acima, exigindo, no entanto, a reinstalação da atmosfera controlada após cada renovação da atmosfera. A pressão parcial de $\mathrm{CO}_{2}$ no interior da minicâmara com o tratamento 6 foi corrigida diariamente, através da injeção de $\mathrm{N}_{2}$, gerado por um equipamento PSA ("Pressure Swing Adsorption"). Nos demais, a absorção do $\mathrm{CO}_{2}$ foi realizada com absorvedor de $\mathrm{CO}_{2}$ com uma solução de $\mathrm{NaOH}$ (40\%), acionado automaticamente pelo sistema de controle de gases. Foram realizadas, a cada 10 dias, determinações da concentração de etileno no interior das minicâmaras.

A análise laboratorial dos frutos foi realizada após oito meses de armazenamento, quando se avaliou a respiração, produção de etileno, cor de fundo da epiderme, firmeza de polpa, sólidos solúveis totais, acidez titulável e incidência de podridões, conforme metodologia descrita em BRACKMANN et al. (2003). As variáveis expressas em porcentagem foram transformadas pela fórmula arc.sen $\sqrt{\mathrm{x} / 100}$, para serem submetidas à análise da variância, sendo as médias dos tratamentos comparadas ente si pelo teste de Duncan em nível de 5\% de probabilidade de erro.

A renovação diária da atmosfera durante o resfriamento e mensal durante o armazenamento proporcionou frutos com maior firmeza de polpa (Tabela 1). Esta resposta não deve estar relacionada à concentração de etileno dentro da câmara, cuja concentração de $29,86 \mu \mathrm{L} \mathrm{L}^{-1}$ foi semelhante a dos outros tratamentos. De acordo com BRACKMANN et al. (2003), níveis de etileno acima de $0,4 \mu \mathrm{L} \mathrm{L}^{-1}$ são suficientes para desencadear o processo de amaciamento da polpa em maçãs 'Gala', embora de forma bastante lenta. Os teores de sólidos solúveis totais foram maiores nos frutos dos 
Tabela 1 - Qualidade físico-química de maçãs 'Gala' armazenadas durante oito meses em atmosfera controlada ( $1,2 \mathrm{kPa}$ de $\mathrm{O}_{2}$ e $2,5 \mathrm{kPa}$ de $\left.\mathrm{CO}_{2}\right)$ a $0,5^{\circ} \mathrm{C}( \pm 0,1)$. Santa Maria, RS, 2002.

\begin{tabular}{|c|c|c|c|c|c|c|}
\hline Tratamentos & $\begin{array}{l}\text { Firmeza de } \\
\text { polpa }(\mathrm{N})\end{array}$ & $\begin{array}{l}\text { Sólidos solúveis } \\
\text { totais ( }{ }^{\circ} \text { Brix) }\end{array}$ & Podridão (\%) & $\begin{array}{c}\text { Respiração } \\
\left(\mathrm{mLCO}_{2} \mathrm{~kg}^{-1} \mathrm{~h}^{-1}\right)\end{array}$ & $\begin{array}{l}\text { Síntese de etileno } \\
\qquad\left(\mu 1 \mathrm{~kg}^{-1} \mathrm{~h}^{-1}\right)\end{array}$ & $\begin{array}{c}\text { Etileno nas } \\
\text { câmaras }{ }^{1}\left(\mu \mathrm{L} \mathrm{L}^{-1}\right)\end{array}$ \\
\hline Controle (sem renovação) & $48,6 b^{3}$ & $11,8 b$ & $54,6 \mathrm{a}$ & $12,1 \mathrm{a}$ & $1,41 \mathrm{cb}$ & 28,9 \\
\hline $\begin{array}{l}\text { RA diariamente durante o } \\
\text { resfriamento }\end{array}$ & $44,5 b$ & $12,3 \mathrm{a}$ & $51,0 \mathrm{ab}$ & $10,2 b$ & $1,28 \mathrm{cb}$ & 28,9 \\
\hline $\begin{array}{l}\text { RA diariamente e } \\
\text { mensalmente durante } \\
\text { armazenamento em AC }\end{array}$ & $57,6 \mathrm{a}$ & $12,3 \mathrm{a}$ & $28,5 \mathrm{bc}$ & $9,4 \mathrm{~b}$ & $2,50 \mathrm{a}$ & 29,9 \\
\hline $\begin{array}{l}\text { RA mensal durante o } \\
\text { armazenamento em AC }\end{array}$ & $47,7 b$ & $12,3 \mathrm{a}$ & $29,6 \mathrm{bc}$ & $10,0 \mathrm{~b}$ & $1,79 b$ & 29,9 \\
\hline $\begin{array}{l}\text { Injeção de } 50 \mu \mathrm{L} \mathrm{L}^{-1} \text { de etileno } \\
\text { no interior da câmara }\end{array}$ & $41,8 b$ & $12,1 \mathrm{ab}$ & $24,5 \mathrm{c}$ & $9,4 b$ & $1,33 \mathrm{cb}$ & 46,1 \\
\hline $\begin{array}{l}\text { Atmosfera dinâmica (injeção de } \\
\mathrm{N}_{2} \text { para a remocão do } \mathrm{CO}_{2} \text { ) }\end{array}$ & $46,8 b$ & $12,4 \mathrm{a}$ & $41,3 \mathrm{abc}$ & $10,1 b$ & $0,94 \mathrm{c}$ & 5,6 \\
\hline Coeficiente de Variação (\%) & 13,59 & 2,15 & 25,64 & 9,09 & 29,24 & - \\
\hline
\end{tabular}

${ }^{1}$ Valores médios das concentrações de etileno presentes nas minicâmaras de armazenamento durante os oito meses de armazenamento.

${ }^{2} \mathrm{RA}=$ Renovação da atmosfera.

${ }^{3}$ Médias seguidas pela mesma letra não diferem entre si pelo teste de Duncan em nível de 5\% de probabilidade de erro.

tratamentos com renovação da atmosfera $(2,3$ e 4$)$ e atmosfera dinâmica (6). Provavelmente, as injeções de ar e de nitrogênio removeram a umidade presente na atmosfera das minicâmaras, provocando uma maior desidratação dos frutos e uma maior concentração dos sólidos solúveis totais (dados não avaliados). A incidência de podridões foi menor nos frutos dos tratamentos com renovação mensal da atmosfera, com ou sem renovação durante o resfriamento, e com $50 \mu \mathrm{L} \mathrm{L}^{-1}$ de etileno (Tabela 1). PARSONS et al. (1974) verificaram um aumento na incidência de podridões em tomates com a interrupção da atmosfera semanalmente, através da exposição dos frutos ao ar por 16 horas. Os frutos submetidos à renovação da atmosfera, injeção de $50 \mu \mathrm{L} \mathrm{L} \mathrm{L}^{-1}$ de etileno na câmara e à atmosfera dinâmica apresentaram menores valores de respiração (Tabela 1). NEUWIRTH (1988), trabalhando com maçãs 'Golden Delicious', armazenadas em atmosfera controlada e submetidas à ventilação das câmaras com ar natural durante três semanas, verificou maior produção de $\mathrm{CO}_{2} \mathrm{e}$ substâncias voláteis, quando a ventilação foi iniciada durante o climatério dos frutos. A ventilação iniciada em outros momentos não apresentou esses mesmos efeitos. Em relação à síntese de etileno, os frutos submetidos à renovação diariamente e mensalmente durante o armazenamento em atmosfera controlada apresentaram os menores valores de síntese de etileno (Tabela 1). A acidez titulável e a cor de fundo da epiderme não diferiram entre os tratamentos avaliados, ao final do período de armazenamento (dados não apresentados).

Nenhuma das técnicas avaliadas permitiu reduzir suficientemente os níveis de etileno nas câmaras de armazenamento. Tendo em vista que a renovação da atmosfera implica altos custos na aquisição de nitrogênio, deve ser analisado se o ganho em firmeza de polpa compensa estes gastos adicionais. Provavelmente, a absorção do etileno trará um benefício igual ou maior com um menor custo.

\section{REFERÊNCIAS BIBLIOGRÁFICAS}

BRACKMANN, A. Produção de etileno, $\mathrm{CO}_{2}$ e aroma de cultivares de maçã. Revista Brasileira de Fruticultura, Cruz das Almas, v.14, n.1, p.103-108, 1992.

BRACKMANN, A. et al. Armazenamento de maçã 'Gala' em atmosfera controlada com remoção de etileno. Ciência Rural, Santa Maria, v.33, n.4, p.647-650, 2003.

BRACKMANN, A.; LUNARDI, R. Influência de métodos de manutenção do nível de $\mathrm{CO}_{2}$ na qualidade de maçã 'Fuji' em atmosfera controlada. Revista Brasileira de Agrociência, v.2, n.3, p.171-174, 1996.

KADER, A.A. Postharvest technology of horticultural crops. California : Division of Agriculture and Natural Resources, 1992. 292p.

NEUWIRTH, G.R. Respiration and formation of volatile flavour substances in controlled atmosphere-stored apple after periods of ventilation at different times. Archiv fur Gartenbau, v.36, p.417422, 1988.

PARSONS, C.S. et al. Storage of mature-green tomatoes in controlled atmospheres. Journal American Society for Horticultural Science, Alexandria, v.95, p.791-794, 1974.

Ciência Rural, v.35, n.2, mar-abr, 2005. 